\title{
Teknologi dan Teknik Sistem Komputasi Pervasif dalam Sistem Layanan Kesehatan: Studi Literatur Sistematis
}

\author{
Danang Wahyu Utomo ${ }^{1}$, Egia Rosi Subhiyakto ${ }^{2}$ \\ Fakultas Ilmu Komputer, Universitas Dian Nuswantoro \\ Jl. Nakula I No. 5-11 Semarang, Jawa Tengah 50131 \\ E-mail: 1danang.wu@dsn.dinus.ac.id, ²egia@dsn.dinus.ac.id
}

Masuk: 15 Januari 2016; Direvisi: 3 Februari 2016; Diterima: 9 Februari 2016

\begin{abstract}
Technology of pervasive computing can be applied in daily activities such as sport, education, game and public interest such as public health. In healthcare system, the issues about high cost and errors in reviewing of patient record are still a major topic for healthcare provider (hospital). The technology of pervasive computing was developed to address these issues. This study will discuss the technology to support healthcare system. The main purpose is that users need to know the technology and its characteristics in order to prevent fatal actions in its use. The integration of different kinds of technology such as mobile devices, wireless networks, sensors, and wearable technologies is able to give better healthcare service than the technology itself.
\end{abstract}

Keywords: Technology, Pervasive Healthcare System, Systematic Literature Review.

\begin{abstract}
Abstrak. Teknologi komputasi pervasif dapat diterapkan dalam aktifitas manusia mulai dari kebutuhan pribadi seperti olahraga, belajar, permainan dan kepentingan umum seperti kesehatan umum. Dalam sistem layanan kesehatan,isu tentang biaya yang tinggi, adanya kesalahan dalam review data pasien masih menjadi topik utama bagi penyedia layanan kesehatan (rumah sakit). Teknologi komputasi pervasif dikembangkan untuk mengatasi masalah tersebut. Dalam makalah ini akan dibahas mengenai teknologi dan karakteristiknya dalam mendukung sistem layanan kesehatan. Tujuan utama adalah pengguna harus mengetahui teknologi dan karakteristiknya agar tidak terjadi tindakan fatal dalam penggunaanya. Integrasi antar teknologi seperti mobile device, wireless network, sensor, dan wearable technologies mampu memberikan layanan kesehatan yang lebih baik dibanding teknologi itu sendiri.
\end{abstract}

Kata Kunci: Teknologi, Sistem Layanan Kesehatan Pervasif, Studi Literatur Sistematis.

\section{Pendahuluan}

Teknologi komputasi pervasif (pervasive computing) dapat dilakukan dalam kegiatan sehari-hari seperti olahraga, pendidikan, dan kesehatan. Teknologi-teknologi yang diusulkan juga mampu mendukung di dalam berbagai domain seperti logistik, kesehatan, permainan, dan sistem cerdas (Subhiyakto, dkk., 2015). Sebagai contoh, komputasi pervasif dapat diterapkan pada pengukuran performa atlet, keterampilan psikomotorik (Fogtmann, dkk., 2011), pengembangan pada model pembelajaran bagi anak-anak (Laine, dkk., 2010), dan pelayanan kesehatan terhadap diagnosis penyakit (Bayraktar, dkk., 2011). Dalam bidang kesehatan, komputasi pervasif fokus pada pelayanan kesehatan seperti membantu pasien dengan keterbatasannya (pasien cacat) yang sedang melakukan pemeriksaan penyakitnya.

Pengembangan teknologi pada sistem layanan kesehatan pervasif memungkinkan pelayanan pada rumah sakit ke pelayanan rumah (home care) dan pelayanan bantuan (assistance care). Tujuan dari sistem pervasif adalah menyediakan pelayanan kesehatan kapanpun, dimanapun dan untuk siapapun terutama ke orang yang memiliki keterbatasan (orang cacat). Adanya penerapan teknologi komputasi pervasif seperti perangkat mobile, wireless, jaringan, sensor dan beberapa wearable technology mengindikasikan bahwa teknologi tersebut mampu mendukung sistem layanan kesehatan kepada pasien khususnya manula dan pasien cacat. Sebagai contoh, pasien tidak perlu datang ke rumah sakit untuk melakukan check-up rutin. Teknologi komputasi pervasif memfasilitasi pasien dan dokter untuk melakukan pemeriksaan 
(check-up rutin) di tempat berbeda. Teknologi ini membantu pasien untuk mengetahui keluhankeluhan awal mengenai penyakitnya dan selanjutnya diberikan kepada dokter untuk dilakukan diagnosis penyakit. Tanpa tatap muka, dokter dapat memberikan diagnosis langsung kepada pasien cacat terkait keluhan dari pasiennya.

Teknologi diagnosis penyakit memiliki peranan penting dalam sistem layanan kesehatan seperti pencegahan dini dari penyakit, pengawasan pada pasien dalam rumah dan membantu dokter dalam memberikan umpan balik yang cepat kepada pasien khususnya yang membutuhkan penanganan cepat untuk segera ditindaklanjuti. Adanya teknologi tersebut merupakan tantangan bagi penyedia layanan kesehatan bagaimana menggunakan teknologi yang sesuai dengan pelayanan kesehatan kepada pasien. Apakah teknologi yang saat ini digunakan sudah tepat untuk diberikan kepada pasien?

\section{Fokus Studi}

Karakteristik tiap pasien berbeda dalam hal ini teknologi yang diusulkan harus mampu memahami karakteristik pasien dan penyakitnya. Muras, dkk. (2006) menyatakan bahwa teknologi yang diusulkan harus mampu mengatasi permasalahan dalam pelayanan kesehatan yang melibatkan pasien, lingkungan, dan teknologi lainnya. Artinya, sebuah teknologi harus mampu mendukung diagnosis penyakit berdasarkan karakteristik pasien dan penyakitnya. Pernyataan tersebut menjadikan dasar fokus studi yaitu: (1) Apa saja karakteristik teknologi komputasi pervasif dalam sistem layanan kesehatan pervasif? dan (2) Teknologi apa saja yang mampu mendukung sistem layanan kesehatan pervasif berdasarkan karakteristiknya?

\section{Metode Review}

\subsection{Identifikasi Literatur yang Relevan}

Strategi dalam pencarian literatur dapat didefinisikan menggunakan kata kunci berdasarkan makna dari masalah. Pencarian kata kunci menggunakan BOOLEAN OR dan AND untuk mengurangi hasil yang tidak relevan. Pada makalah ini kata kunci yang digunakan adalah: (1) Pervasive healthcare system (2) Pervasive healthcare application (3) Characteristics of technology (4) Technology (5) Diagnosis (6) Illnesses. Semua kata kunci tersebut digunakan dalam pencarian literatur sebagai berikut: (Pervasive healthcare system OR Pervasive healthcare application) AND (Characteristic of technology) AND (Diagnosis) AND (Illnesses). Dalam studi ini, pencarian literature menggunakan enam online database: Science Direct, IEEE Explore, ACM Digital Library, Scopus, EBSCO Host, Engineering Village.

\subsection{Pemilihan Penelitian}

Pemilihan penelitian dilakukan untuk mendapatkan literatur yang sesuai dengan topik penelitian. Pemilihan penelitian terdiri dari dua kriteria yaitu kriteria inklusi dan kriteria eksklusi. Kriteria inklusi: (1) studi yang membahas tentang diagnosa penyakit dalam dan teknik yang diusulkan dalam sistem layanan kesehatan pervasif. (2) studi tentang teknologi pada sistem layanan kesehatan pervasif. (3) studi tentang karakteristik teknologi pada sistem layanan kesehatan pervasif. Kriteria eksklusi: (1) studi di luar teknologi pada sistem layanan kesehatan pervasif. (2) studi tentang komputasi pervasif, tetapi di luar topik layanan kesehatan.

\section{Hasil Sintesis}

\subsection{Karakteristik Teknologi dalam Sistem Layanan Kesehatan}

Pada studi literatur sistematis ini dalam sistem layanan kesehatan fokus pada teknologi pada sistem layanan kesehatan dan karakteristik teknologi tersebut. Pada Gambar 1 didapat bahwa karakteristik teknologi terbagi menjadi dua yaitu karakteristik area dan karakteristik assistance. Tiap karakteristik area dan assistance memiliki sistem layanan yang berbeda. Pasien, dokter, maupun perawat diharapkan mampu memahami jenis-jenis dari teknologi yang diusulkan untuk mengurangi kesalahan dalam penggunaan teknologi tersebut. Kesalahan dalam penggunaan teknologi bisa berakibat fatal bagi pengguna, terutama pasien dengan keterbatasan. 


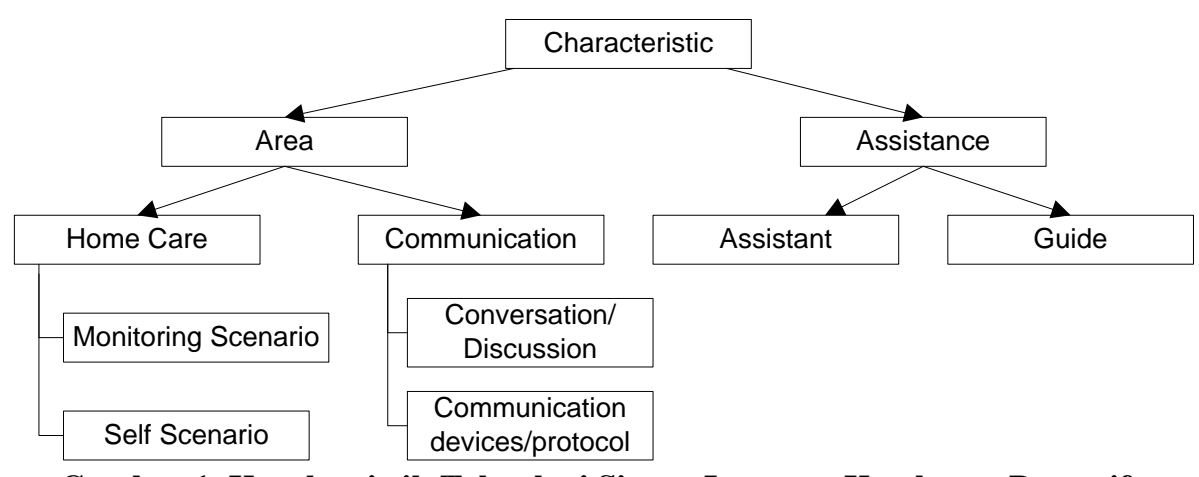

Gambar 1. Karakteristik Teknologi Sistem Layanan Kesehatan Pervasif

\subsubsection{Karakteristik Area}

Karakteristik area menyediakan teknologi yang memberikan layanan kesehatan kapanpun dan dimanapun. Teknologi pervasif pada karakteristik area fokus pada bagaimana seseorang peduli terhadap kesehatannya.

\subsubsection{Teknologi pada Home Care}

Layanan home care merupakan layanan kesehatan yang memungkinkan proses layanan terapi, kontrol atau pengobatan rutin dalam rumah. Karakteristik monitoring scenario memfasilitasi pasien jika dalam kondisi dimana pasien tidak dapat berinteraksi atau tidak dapat menggunakan teknologi apapun, pengasuh berperan sebagai penghubung antara pasien dengan dokter. Beberapa contoh teknologi dalam skenario pemantauan adalah web service, sensor, dan integrasi web service dengan teknologi lainnya. Web services Moritz, dkk. (2009) membantu layanan home care untuk memonitor parameter vital pasien yang dapat diobservasi melalui perangkat mobile. Teknologi ini dapat diintegrasikan dengan teknologi lainnya seperti sensor yang ditujukan kepada pasien dalam kondisi darurat dan membutuhkan pertolongan dokter secara cepat. Selain sensor, web services juga dilengkapi web camera yang bertujuan untuk memfasilitasi antara dokter dan pasien untuk konsultasi secara interaktif. Website real time Yuan \& Herbert (2011b) untuk memantau perkembangan kondisi pasien, Medjahed, dkk. (2009) menggunakan logika fuzzy untuk mengenali dan memantau kegiatan aktifitas dari manula dengan menggunakan teknologi sensor.

Self scenario menyediakan pelayanan kesehatan kepada pasien untuk mengatur kondisinya secara individual. Alemdar \& Ersoy (2010) meminimalkan kebutuhan pengasuh dalam layanan kesehatan rumah dan menyediakan pengawasan berkala untuk memantau pasien dengan penyakit kronisnya. Teknologi yang diusulkan harus mampu mengenali karakteristik dari tiap orang seperti penyakit, daya tahan tubuh, golongan darah, dan kondisi pasien. Sebagai contoh, Srivastava, dkk. (2015) mendiskusikan tentang peran self care dalam manajemen penyakit diabetes, bagaimana seseorang dapat memantau perkembangan penyakit diabetes dan menentukan prediksi kedepan tentang perkembangan hasil yang positif, yaitu mengurangi kadar diabetes dalam tubuh. Bromuri, dkk. (2011) menerapkan aplikasi mobile untuk membantu pasien hamil dengan penyakit gestational diabetes mellitus (GDM). Aplikasi ini menyediakan pengawasan berkala dan memfasilitasi dokter dalam memberikan diagnosa penyakit ke pasien hamil. Pasien hamil dengan keterbatasannya (resiko untuk pergi ke rumah sakit) tetap dapat menjalankan aktivitas perawatan rutinnya mengenai penyakit GDM-nya. Berdasarkan contoh tersebut mengindikasikan bahwa pelayanan kesehatan self scenario dibutuhkan banyak orang untuk tetap menjalankan aktivitas layanan kesehatan meskipun dilakukan secara individual.

\subsubsection{Communication}

Adanya penderita penyakit kronis dan meningkatnya biaya dalam layanan kesehatan dan adanya kelemahan pada teknologi home care yaitu kurangnya karakteristik ubiquity (mampu digunakan dimanapun dan kapanpun) menjadi fokus utama pengembangan teknologi 
karakteristik komunikasi dalam menyediakan layanan kesehatan secara berkala dan memberikan umpan balik medis dalam kehidupan sehari-hari. Umpan balik mengacu pada bagaimana teknologi mampu digunakan sebagai komunikasi interaktif yaitu sebagai alat diskusi antara pasien, perawat maupun dokter. Semua aktifitas layanan kesehatan dapat diintegrasikan ke perangkat seluler (PDA, smartphone, dan perangkat seluler mini lainnya) untuk menyediakan informasi (sejarah pasien, medis, dan hasil tes) ke dokter, perawat, dan pasien. Bayraktar, dkk. (2011) menggunakan perangkat seluler untuk mendukung diagnosa dokter dan mampu memberikan tanggapan yang cepat kepada pasien penderita diabetes. Karan, dkk. (2012) mengusulkan arsitektur client dan server yaitu antara perangkat seluler sebagai client dengan PC sebagai server.

Teknologi karakteristik komunikasi juga fokus terhadap protokol komunikasi yang dapat digunakan untuk integrasi dengan teknologi lainnya. Delmastro (2012) melakukan survey tentang teknologi komunikasi wireless menyatakan alasan pengembangan teknologi ini adalah antara pasien, dokter, perawat maupun pengasuh harus menjalin komunikasi interaktif, mendukung pemantauan secara real time, dan memberikan infomasi mengenai perkembangan kondisi pasien, hasil laboratorium, catatan medis, dan informasi asuransi yang dapat diakses kapanpun dan dimanapun. Ghose, dkk. (2012) menggunakan perangkat seluler untuk mendukung penyampaian informasi ke server yang bertujuan menyediakan interaktif portal layanan kesehatan kepada pasien. Teknologi yang diusulkan mampu menyimpan data dari peralatan medis seperti sensor, ECG, pengukur tekanan darah, pengukur berat badan. TorradoCarvajal, dkk. (2012) menyatakan bahwa adanya perubahan konsep komunikasi ke wireless system menyempurnakan sistem layanan kesehatan pervasif secara ubiquity. Integrasi teknologi wireless dan mobile meningkatkan layanan pemantauan secara berkala kepada manula dan penderita penyakit kronis. Integrasi antar teknologi mengindikasikan bahwa adanya peningkatan kualitas dalam layanan kesehatan pervasif terutama dari sisi komunikasi.

\subsubsection{Karakteristik Assistance}

Teknologi dengan karakteristik assistance adalah memberikan layanan kesehatan kepada pengguna dengan beberapa tugas, petunjuk atau pedoman, dan sistem pengingat.

\subsubsection{Assistant}

Penyakit dengan kondisi kronis seperti diabetes, asma, kanker, dan tekanan darah tinggi merupakan penyakit dengan efek yang lama dan membutuhkan layanan kesehatan dengan karakteristik long-term diagnostic (diagnosa dalam kurun waktu yang lama), patient-remote monitoring (pemantauan pasien secara berkala). Bagi pasien dengan kondisi keterbatasannya (pasien cacat, pasien lumpuh, stroke, tidak mampu berpindah ke tempat lainnya) memiliki kekurangan atau ketidakmampuan dalam menggunakan teknologi seperti home care, wireless, dan teknologi komunikasi lainnya, pengasuh berperan dalam membantu orang atau pasien dalam mempelajari teknologi yang digunakan dalam layanan kesehatan. Namun, ada beberapa kelemahan dalam melibatkan pengasuh yaitu pengasuh kadang melakukan kelalaian yang menyebabkan kondisi orang semakin kritis, pengasuh tidak memahami teknologi yang harus digunakan. Perkembangan terkini mengindikasikan bahwa teknologi dalam komputasi pervasif mampu diterapkan dalam layanan kesehatan seperti long-term diagnostic, patient-remote monitoring. Teknologi RFID (Tu, dkk., 2009) digunakan untuk mengidentifikasi dan melacak objek yang dicari. Teknologi ini membantu pengasuh dalam melakukan pemantauan secara berkala terkait posisi orang. Yuan \& Herbert (2012) menggunakan BAN (Body Area Network) salah satu wearable technologies, menyediakan layanan kesehatan berupa sensor medis dan temperatur yang mampu membaca kondisi tubuh atau psikologi orang. Teknologi BAN sangat cocok bagi manula dan orang dengan keterbatasannya dalam menyelesaikan tugas.

\subsubsection{Guide}

Teknologi karakteristik guide memberikan informasi berupa direksi, langkah-langkah yang harus dilakukan untuk mengatur tugasnya atau bagi pasien home care membantu 
menyelesaikan perawatan rutinnya. Layanan Smart RFID Venkatalakshmi, dkk. (2011) membantu perawat untuk melakukan pengecekan data pasien dan mendukung pekerjaan dokter untuk melakukan diagnosa penyakit. Layanan kesehatan ini juga mendukung pekerjaan perawat terkait pemberian obat kepada pasien. Bagi manula dan pengasuh, teknologi dengan karakteristik guide sangat membantu untuk mempelajari dan memahami teknologi tersebut. Rabie \& Klopper (2015) mengusulkan suatu pedoman bagi orang tua, perawat, dan sektor kesehatan umum. Pedoman ini digunakan untuk memberikan pencegahan dini kepada orang tua yang sering melakukan kelalaian dalam perawatan rutinnya. Selain itu, pedoman ini juga dapat membantu perawat dan pekerja dalam layanan kesehatan umum untuk meningkatkan kualitas kesehatan dan hidup dari orang, terutama manula.

\subsection{Teknologi dalam Sistem Layanan Kesehatan Pervasif}

Teknologi komputasi pervasif seperti wireless, networks, sensors, mobile application, dan mobile device dikembangkan untuk memberikan kualitas pada sistem layanan kesehatan. Berdasarkan Tabel 1, menunjukkan bahwa teknologi mobile memiliki banyak peran dalam meningkatkan sistem layanan kesehatan. Muncul integrasi-integrasi antara mobile device dengan PC dimana integrasi tersebut didukung oleh beberapa teknik, metode, maupun algoritma untuk menentukan komputasi yang diinginkan. Sebagai contoh, penggunaan neural network, $A N N$ untuk mendukung diagnosa dokter. Bayraktar, dkk. (2011) menggunakan ANN sebagai classifier untuk menentukan karakteristik penyakit berdasarkan kondisi orangnya. Hasil akhir dari komputasi tersebut dilaporkan ke PDA pasien. Perkembangan selanjutnya, adanya integrasi antara mobile device dengan teknologi lain seperti wireless, sensors, dan wearables technologies. Kulkarni \& Ozturk (2011) melakukan integrasi antara mobile dengan sensor berfokus bagaimana melakukan deteksi awal penyakit dan akses pervasif dengan tanda pesan di perangkat mobile-nya. Integrasi antara mobile device dengan wireless sensor networks juga mampu mendukung pemantauan secara berkala kepada anak-anak dan khususnya manula tanpa bantuan pengasuh. Chen, dkk. (2011) mengusulkan integrasi antara wireless broadband medical dengan mobile station yang menerapkan teknik cloud computing ke perangkat mobile. Pengembangan teknologi tersebut mengindikasikan bahwa integrasi antara teknologi mobile dengan wireless network mampu memberikan layanan kesehatan terutama bagi orang yang membutuhkan layanan kesehatan home care.

Tabel 1. Teknologi dalam layanan kesehatan pervasif

\begin{tabular}{|c|c|c|c|c|}
\hline & \multicolumn{2}{|c|}{ Area } & \multicolumn{2}{|c|}{ Assistance } \\
\hline & Home Care & Communication & Assistant & Guide \\
\hline $\begin{array}{l}\text { Mobile } \\
\text { device }\end{array}$ & $\begin{array}{l}\text { (Guo, dkk., 2015), (Preuveneers \& } \\
\text { Berbers 2008), (Laine, dkk., 2010), } \\
\text { (Gravenhorst, dkk., 2014), } \\
\text { (Bardram, dkk., 2013), (Lee, } \\
\text { 2012), (Chen, dkk., 2011), (Ghose, } \\
\text { dkk., 2012), (Karan, dkk., 2012), } \\
\text { (Kulkarni \& Ozturk 2011), }\end{array}$ & 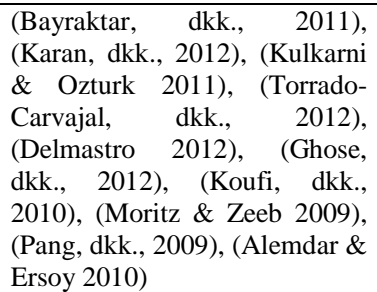 & - & $\begin{array}{l}\text { (Venkatalaksh } \\
\text { mi, dkk., 2011) }\end{array}$ \\
\hline $\begin{array}{l}\text { Wireless } \\
\text { network }\end{array}$ & $\begin{array}{l}\text { (Koufi, dkk., 2010), (Niyato, dkk., } \\
\text { 2009), (Yuan \& Herbert 2011a) }\end{array}$ & $\begin{array}{l}\text { (Delmastro 2012), (Alemdar \& } \\
\text { Ersoy 2010), (Torrado- } \\
\text { Carvajal, dkk., 2012), (Alemdar } \\
\text { \& Ersoy 2010), (Kulkarni \& } \\
\text { Ozturk 2011) }\end{array}$ & - & - \\
\hline Sensor & $\begin{array}{l}\text { (van der Linden, dkk., 2011), } \\
\text { (Postolache, dkk., 2011), (Kim, } \\
\text { dkk., 2013), (Maitland, dkk., } \\
\text { 2011), (Pang, dkk., 2009), }\end{array}$ & - & $\begin{array}{l}\text { (Tu, dkk., 2009), } \\
\text { (Postolache, dkk., } \\
\text { 2011), (Yuan \& } \\
\text { Herbert 2011a), } \\
\text { (Kulkarni \& Ozturk } \\
\text { 2011) }\end{array}$ & $\begin{array}{l}\text { (van der } \\
\text { Linden, dkk., } \\
\text { 2011), } \\
\text { (Venkatalaksh } \\
\text { mi, dkk., 2011) }\end{array}$ \\
\hline $\begin{array}{l}\text { Wearable } \\
\text { technologies }\end{array}$ & $\begin{array}{l}\text { (Yuan \& Herbert 2011a), (Salih, } \\
\text { dkk., 2011), (Ziefle \& Rocker } \\
\text { 2010) }\end{array}$ & - & $\begin{array}{l}\text { (Yuan \& Herbert } \\
\text { 2011a) }\end{array}$ & - \\
\hline
\end{tabular}


Teknologi sensor juga dapat mendukung skenario pemantauan menggunakan gelombang sensor, radio. Teknologi RFID adalah salah satu teknologi dalam layanan kesehatan yang menggunakan gelombang radio. RFID dapat digunakan untuk memantau keadaan sekitar, menemukan lokasi orang berdasarkan pancaran gelombang radio. Venkatalakshmi, dkk. (2011) menerapkan RFID sebagai smart assistant untuk membantu pekerjaan perawat dalam memberikan obat berdasarkan karakteristik penyakit. RFID melakukan capture ID pasien yang nantinya akan ditampilkan bersamaan dengan obat yang telah direkomendasikan. Tu, dkk. (2009) menggunakan RFID untuk identifikasi dan menemukan lokasi berdasarkan objek yang telah ditandai. RFID memberikan pencegahan awal terjadinya kelalaian orang tua atau kejadian yang buruk dalam rumah.

Wearable technologies merupakan teknologi yang berinteraksi langsung dengan kondisi tubuh orang dimana mampu memahami karakteristik orang. CARA (Context Aware Real Time Application) merupakan salah satu penerapan dari wearable technologies yang menyediakan layanan kesehatan secara real time. Yuan \& Herbert (2011a) menerapkan sistem CARA dengan menggunakan wireless medical BAN (Body Area Network), internet-connected PC, dan sensor untuk gerak perpindahan, melakukan pengukuran psikologi orang dan hasilnya disimpan dalam server. Chen, dkk. (2011) menerapkan sistem CARA untuk skenario pemantauan berkala menggunakan adobe flash plugin. Yuan \& Herbert (2012) menggunakan logika fuzzy berdasarkan reasoning framework untuk mendapat akurasi dalam deteksi situasi darurat.

Adanya integrasi antara mobile device, wireless network, sensor, dan wearable technologies memberikan pencegahan dini, kelalaian, kejadian buruk dalam menjalani perawatan rutin, pemantauan kondisi fisik dan umpan balik yang cepat.

\section{Diskusi}

\subsection{Isu dan Tantangan dalam Sistem Layanan Kesehatan}

Dari teknologi yang diusulkan dan diterapkan pada sistem layanan kesehatan, terdapat beberapa isu-isu yang dihadapi pengguna seperti isu tentang keamanan, privasi, kesulitan dalam menggunakan sistem. Banyak ancaman-ancaman yang menyerang sistem untuk mendapatkan data dan informasi, merusak sistem layanan kesehatan yang ada dengan cara serangan malware (virus, worm, Trojan horse) yang menyerang program komputer tanpa ijin, serangan Denial of Service yang mengganggu aktifitas komunikasi dimana bertujuan untuk merusak atau menghilangkan hak akses pengguna. Untuk mengatasi isu-isu terkait keamanan dan privasi tersebut dapat menggunakan solusi penggunaan firewall, data authentication, teknik enkripsi. Germano, dkk. (2009) menggunakan teknik enkripsi untuk menerapkan embedding system dalam meningkatkan keamanan aplikasi biomedis. Salih, dkk. (2011) menggunakan teknik enkripsi untuk proteksi privasi sistem layanan pemantauan, melindungi data medis dan metadata polis privasi. Skema teknik enkripsi mampu menjadi alat untuk mencegah adanya ancaman dan serangan terhadap data dan informasi suatu rumah sakit. Teknik enkripsi juga mampu melindungi otentifikasi suatu sistem. Hal ini sangat penting untuk mencegah adanya klaim sistem dari pihak lain.

Tantangan yang ada adalah menerapkan teknologi-teknologi tersebut kepada pengguna yang minim pengetahuan tentang teknologi. Perawat atau pengasuh dengan minim pengetahuan tentang teknologi, memiliki kemungkinan kesalahan atau kelalaian dalam penggunaannya yang dapat berakibat fatal ke pasien. Untuk mengatasi isu tersebut dapat menggunakan skema desain dan arsitektur dalam pengembangan sistem, integrasi antar sistem, dan petunjuk penggunaan sistem. Venkatalakshmi, dkk. (2011) menggunakan integrasi antar mobile dan RFID untuk mencegah kelalaian perawat dalam memberikan obat kepada pasien. Rabie \& Klopper (2015) mengusulkan petunjuk dalam penggunaan sistem layanan kesehatan untuk mencegah kelalaian dalam proses self care.

\subsection{Teknologi dalam Sistem Layanan Kesehatan 5.2.1. Home Care}

Pada Gambar 2 didapat teknologi pada home care dibagi menjadi dua yaitu monitoring 
scenario dan self scenario. Karakteristik teknologi dalam layanan kesehatan home care fokus bagaimana mengenali tingkah laku manusia seperti berdiri, berjalan, berlari, dan melakukan aktifitas lainnya. Teknologi home care memiliki karakteristik sebagai berikut: 1) Teknologi mampu mengenali dan mengidentifikasi aktifitas sehari-hari. 2) Teknologi mampu mengidentifikasi deteksi pergerakan dan lokasi orang. 3) Teknologi memantau status medis.

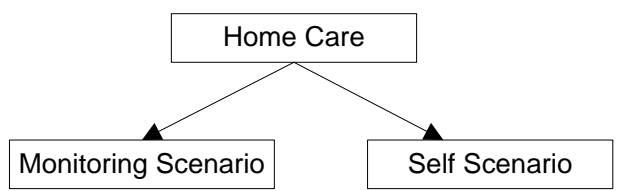

\section{Gambar 2. Kategori Layanan Kesehatan Home Care}

\subsubsection{Monitoring Scenario}

Monitoring scenario berfokus bagaimana parameter dari pasien dapat disimpan dalam database server melalui device yang dilakukan dalam rumah. Skenario ini membutuhkan pengasuh untuk menyelesaikan tugas dan perawatan rutin. Cocok bagi orang dengan keterbatasannya untuk tetap melaksanakan perawatan rutinnya dan konsultasi ke dokter. Integrasi antara mobile device, wireless network, dan sensor dapat digunakan untuk mengidentifikasi keadaan darurat seperti serangan jantung, manula jatuh. Sebagai contoh, teknologi sensor dapat menemukan lokasi target, yang selanjutnya hasilnya dikirimkan ke ponsel pengasuh melalui wireless network.

\subsubsection{Self Scenario}

Self scenario berfokus bagaimana teknologi dapat memfasilitasi pasien dalam mempelajari, memahami layanan kesehatan secara individual. Skenario ini dilakukan secara individual, yang berarti tanpa bantuan pengasuh. Teknologi BAN (Body Area Network) merupakan teknologi yang dapat dipakai ke fisik orang untuk melakukan kontrol mengenai kondisi fisik seseorang terkait tekanan darah, suhu tubuh, dan psikologi. Layanan kesehatan secara individual melatih orang untuk peduli kepada perkembangan kesehatannya dan melatih untuk melakukan pencegahan terhadap hal-hal yang menyebabkan kegagalan dalam layanan kesehatan.

\subsubsection{Communication}

Pada Gambar 3 diperoleh teknologi dengan karakteristik communication terdiri dari conversation dan communication devices/protocol.

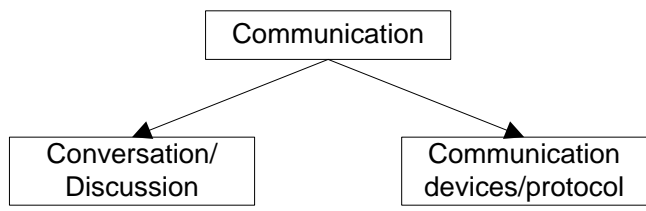

Gambar 3. Kategori Layanan Kesehatan Komunikasi

\subsubsection{Conversation/Discussion}

Kategori conversation menyediakan skenario komunikasi meliputi awalan dan perubahan ide, kualitas pembicaraan, dan penulisan antara satu dengan yang lain baik secara lisan maupun tertulis. Sebagai contoh komunikasi antara dokter dengan pasien melalui web based real time. Orang dapat melakukan diskusi dengan dokternya terkait bagaimana melakukan pencegahan terhadap penyakitnya, bagaimana perawatannya, dan obatnya. Skenario ini memfasilitasi pasien dan dokter untuk bertukar ide melalui percakapan. Web Moritz \& Zeeb (2009), mobile phone Gravenhorst, dkk. (2014) merupakan contoh teknologi dalam kategori conversation/discussion. 


\subsubsection{Communication Devices/Protocol}

Karakteristik communication devices/protocol dapat dikategorikan: patient-centered dan hospital centered (Delmastro, 2012). Patient-centered fokus pada teknologi yang ditekankan ke diri pasien dengan karakteristik yaitu 1) teknologi yang dikenakan di tubuh pasien yang bertujuan untuk pemantauan berkala, 2) rumah sakit sebagai storage dan management data digunakan untuk memberikan umpan balik ke pasien, 3) perangkat mobile sebagai perangkat pribadi sebagai gateway antara teknologi yang dikenakan di tubuh dengan sistem rumah sakit. Hospital centered fokus pada bagaimana pengembangan sistem rumah sakit dilakukan. Karakteristik hospital centered terdiri dari: 1) pusat sub sistem sebagai perangkat medis (integrasi RFID, mobile device), 2) sub sistem rumah sakit diidentifikasi dengan perangkat komunikasi seperti wireless device/protocol, dan 3) sistem informasi rumah sakit sebagai storage dan management data. Secara keseluruhan teknologi komunikasi lebih banyak melibatkan mobile device sebagai perangkat pribadi dalam pengiriman data dan rumah sakit sebagai server sebagai management data medis dalam menyediakan informasi bagi pasien.

\subsubsection{Assistant}

Teknologi pervasif karakteristik assistant didesain untuk membantu atau mendukung kebutuhan pengguna dalam aktifitas sehari-hari. Sebagai contoh, sistem pengingat jadwal periksa, penemuan objek yang hilang, alat bantu untuk membantu menyelesaikan beberapa tugas. Teknologi assistant memiliki karakteristik sebagai berikut: 1) Teknologi menyediakan sistem pengingat mengenai kebutuhan pengguna seperti jadwal periksa, perawatan, dan aksi lainnya. Sistem menyesuaikan karakteristik pengguna dalam menentukan umpan balik antara pengguna dengan sistem. Contoh pesan teks, alarm, sirine. 2) Teknologi menyediakan sistem penempatan orang atau objek. Sistem membantu dalam pencarian objek, menginformasikan kepada pengasuh mengenai letak dari orang (pasien).

\subsubsection{Guide}

Teknologi pervasif karakteristik guide didesain untuk membantu pengguna berupa direksi, langkah-langkah penggunaan alat bantu dalam mengatur dan menganalisa tugas-tugas selama perawatan rutinnya. Selain sebagai petunjuk dalam perawatan rutinnya, teknologi ini juga memberikan pencegahan terhadap tindak kelalaian pengguna terutama bagi manula. Adanya pedoman yang harus dipatuhi selama perawatan, merupakan salah satu cara untuk mencegah terjadinya tindak kelalaian. Teknologi guide memiliki karakteristik sebagai berikut: 1) Teknologi menyediakan aturan atau pedoman untuk menyelesaikan tugasnya dalam aktifitas sehari-hari. Teknologi menyediakan aturan penggunaan atau direksi yang benar. 2) Teknologi menyediakan konsultasi interaktif antara sistem pengguna dan pihak pengguna. Tujuannya, dalam keadaan darurat untuk menginformasikan kepada rumah sakit.

\section{Kesimpulan}

Studi literatur ini menganalisis teknologi dan karakteristiknya dalam sistem layanan kesehatan pervasif. Teknologi komputasi pervasif memberikan peningkatan kualitas pada sistem layanan kesehatan. Tiap teknologi dalam sistem layanan kesehatan pervasif memiliki perbedaan karakteristik dalam memberikan fasilitas layanannya terutama untuk mendukung manula dan orang dengan keterbatasannya. Karakteristik teknologi dibagi menjadi dua yaitu area dan assistance. Karakteristik area membahas teknologi-teknologi yang mampu untuk mengenali dan mengidentifikasi aktifitas rutin dalam lingkungannya dan membantu memantau status perkembangan kondisi pasien. Karakteristik assistance membahas bagaimana teknologi membantu orang dan pengasuh dalam menyelesaikan perawatan rutinnya. Beberapa pengembangan mengindikasikan bahwa teknologi komunikasi lebih banyak diterapkan dalam sistem layanan kesehatan. Teknologi komunikasi mampu menyediakan komunikasi interaktif antar dokter, pasien, dan pengasuh. Penerapan teknologi komunikasi juga melibatkan integrasi dengan teknologi lain untuk memberikan layanan kesehatan yang lebih baik. Dalam studi selanjutnya akan membahas perkembangan teknologi dan karakteristiknya dalam sistem layanan 
kesehatan pervasif. Apa dampak peningkatan teknologi tersebut bagi penyedia layanan kesehatan dan pengguna.

\section{Referensi}

Alemdar, H. \& Ersoy, C., 2010. Wireless sensor networks for healthcare: A survey. Computer Networks, 54(15), pp.2688-2710.

Bardram, J. E., Frost, M., Szántó, K., Faurholt-Jepsen, M., Vinberg, M., \& Kessing, L. V. 2013. Designing mobile health technology for bipolar disorder: a field trial of the monarca system. In Proceedings of the SIGCHI Conference on Human Factors in Computing Systems (pp. 2627-2636). ACM.

Bayraktar, C., Karan, O. \& Gümüşkaya, H., 2011. Diagnosing internal illnesses using pervasive healthcare computing and neural networks. Procedia Computer Science, 3, pp.584-588.

Bromuri, S., Schumacher, M. I., Stathis, K., \& Ruiz, J. 2011. Monitoring gestational diabetes mellitus with cognitive agents and agent environments. In Proceedings of the 2011 IEEE/WIC/ACM International Conferences on Web Intelligence and Intelligent Agent Technology-Volume 02(pp. 409-414). IEEE Computer Society.

Chen, K. R., Lin, Y. L., \& Huang, M. S. 2011. A mobile biomedical device by novel antenna technology for cloud computing resource toward pervasive healthcare. In Bioinformatics and Bioengineering (bibe), 2011 ieee 11th International Conference on (pp. 133-136). IEEE.

Delmastro, F., 2012. Pervasive communications in healthcare. Computer Communications, 35(11), pp.1284-1295.

Fogtmann, M., Grønbæk, K. \& Ludvigsen, M., 2011. Interaction technology for collective and psychomotor training in sports. Proceedings of the 8th International Conference on Advances in Computer Entertainment Technology, pp.13:1-13:8.

Germano, J., Ramalho, R. \& Sousa, L., 2009. On the design of distributed autonomous embedded systems for biomedical applications. Proceedings of the $3 d$ International ICST Conference on Pervasive Computing Technologies for Healthcare, pp.1-8.

Ghose, A., Bhaumik, C., Das, D., \& Agrawal, A. K. 2012. Mobile healthcare infrastructure for home and small clinic. In Proceedings of the 2nd ACM international workshop on Pervasive Wireless Healthcare (pp. 15-20). ACM.

Gravenhorst, F., Muaremi, A., Bardram, J., Grünerbl, A., Mayora, O., Wurzer, G., \& Tröster, G. 2015. Mobile phones as medical devices in mental disorder treatment: an overview. Personal and Ubiquitous Computing, 19(2), 335-353.

Guo, S. H. M., Chang, H. K., \& Lin, C. Y. 2015. Impact of Mobile Diabetes Self-Care System on patients' knowledge, behavior and efficacy. Computers in Industry, 69, 22-29.

Karan, O., Bayraktar, C., Gümüşkaya, H., \& Karlık, B. (2012). Diagnosing diabetes using neural networks on small mobile devices. Expert Systems with Applications, 39(1), 5460.

Kim, S.C., Jeong, Y.S. \& Park, S.O., 2013. RFID-based indoor location tracking to ensure the safety of the elderly in smart home environments. Personal and Ubiquitous Computing, 17(8), pp.1699-1707.

Koufi, V., Malamateniou, F. \& Vassilacopoulos, G., 2010. A system for the provision of medical diagnostic and treatment advice in home care environment. Personal and Ubiquitous Computing, 14(6), pp.551-561.

Kulkarni, P. \& Ozturk, Y., 2011. mPHASiS: Mobile patient healthcare and sensor information system. Journal of Network and Computer Applications, 34(1), pp.402-417.

Laine, T. H., Vinni, M., Sedano, C. I., \& Joy, M. 2010. On designing a pervasive mobile learning platform. Research in Learning Technology, 18(1), pp.3-17.

Lee, C. N. 2012. A home care service platform for mobile healthcare. In 2012 International Conference on Machine Learning and Cybernetics (Vol. 5, pp. 1927-1930). IEEE.

Maitland, J., McGee-Lennon, M. \& Mulvenna, M., 2011. Pervasive healthcare: from orange alerts to mindcare. ACM SIGHIT Record, 1(1), pp.38-40. 
Medjahed, H., Istrate, D., Boudy, J., \& Dorizzi, B. 2009. Human activities of daily living recognition using fuzzy logic for elderly home monitoring. In Fuzzy Systems, 2009. FUZZ-IEEE 2009. IEEE International Conference on (pp. 2001-2006). IEEE.

Moritz, G., Zeeb, E., Golatowski, F., Timmermann, D., \& Stoll, R. (2009, April). Web services to improve interoperability of home healthcare devices. In 2009 3rd International Conference on Pervasive Computing Technologies for Healthcare (pp. 1-4). IEEE.

Muras, J. A., Cahill, V., \& Stokes, E. K. 2006. A taxonomy of pervasive healthcare systems. In 2006 Pervasive Health Conference and Workshops (pp. 1-10). IEEE.

Niyato, D., Hossain, E. \& Camorlinga, S., 2009. Remote patient monitoring service using heterogeneous wireless access networks: Architecture and optimization. IEEE Journal on Selected Areas in Communications, 27(4), pp.412-423.

Pang, Z., Chen, Q. \& Zheng, L., 2009. A pervasive and preventive healthcare solution for medication noncompliance and daily monitoring. 2nd International Symposium on Applied Sciences in Biomedical and Communication Technologies, pp.1-6.

Postolache, O., Girão, P., Pinheiro, E., Madeira, R., Pereira, J. D., Mendes, J., \& Moura, C. 2011. Multi-usage of microwave Doppler radar in pervasive healthcare systems for elderly. In Instrumentation and Measurement Technology Conference (I2MTC), pp. 1-5.

Preuveneers, D. \& Berbers, Y., 2008. Mobile phones assisting with health self-care: a diabetes case study. Proceedings of the 10th international conference on Human computer interaction with mobile devices and services, pp.177-186.

Rabie, T. \& Klopper, H.C., 2015. Guidelines to facilitate self-care among older persons in South Africa. Health SA Gesondheid, 20(1), pp.33-44.

Salih, R.M., Othmane, L. Ben \& Lilien, L., 2011. Privacy Protection in Pervasive Healthcare Monitoring Systems with Active Bundles. 2011 IEEE Ninth International Symposium on Parallel and Distributed Processing with Applications Workshops, pp.311-315.

Srivastava, P.K., Srivastava, S., Singh, A.K., Dwivedi, K.N. 2015. Role of Ayurveda in Management of Diabetes Mellitus. International Research Journal of Pharmacy, 6(1), pp.8-9.

Subhiyakto, E.R., Utomo, D.W. \& Adi, P.W., 2015. Teknologi dan Teknik Sistem Terdistribusi Pervasif dalam Bidang Logistik : Studi Literatur Sistematis. Jurnal Buana Informatika, (2012), 7(2), pp.83-94.

Torrado-Carvajal, A., Rodriguez-Sanchez, M. C., Rodriguez-Moreno, A., Borromeo, S., GarroGomez, C., Hernandez-Tamames, J. A., \& Luaces, M. 2012. Changing communications within hospital and home health care. In 2012 Annual International Conference of the IEEE Engineering in Medicine and Biology Society (pp. 6074-6077). IEEE.

Tu, Y. J., Zhou, W., \& Piramuthu, S. 2009. Identifying RFID-embedded objects in pervasive healthcare applications. Decision Support Systems, 46(2), 586-593.

van der Linden, J., Rogers, Y., Taylor, C., \& Dalgleish, M. 2011. Technology inspired design for pervasive healthcare. In 2011 5th International Conference on Pervasive Computing Technologies for Healthcare (PervasiveHealth) and Workshops (pp. 609-613). IEEE.

Venkatalakshmi, B., Renold, A. P., \& Packiam, R. L. 2011. Smart RFID care [SRC] for pervasive health care system. In Communication Software and Networks (ICCSN), 2011 IEEE 3rd International Conference on (pp. 650-653). IEEE.

Yuan, B. \& Herbert, J., 2012. Fuzzy CARA - A Fuzzy-Based Context Reasoning System For Pervasive Healthcare. Procedia Computer Science, 10, pp.357-365.

Yuan, B., \& Herbert, J. 2011a. Non-intrusive movement detection in cara pervasive healthcare application. In The 2011 international conference on wireless networks, WORLDCOMP (Vol. 11, pp. 360-366).

Yuan, B. \& Herbert, J., 2011b. Web-based real-time remote monitoring for pervasive healthcare. 2011 IEEE International Conference on Pervasive Computing and Communications Workshops (PERCOM Workshops), pp.625-629.

Ziefle, M., \& Röcker, C. (2010). Acceptance of pervasive healthcare systems: A comparison of different implementation concepts. PervasiveHealth, 10, 1-6. 